\title{
VARIASI SPASIAL GETARAN TANAH AKIBAT GEMPABUMI (STUDI KASUS: RANGKAIAN GEMPABUMI SUMATERA UTARA 9-13 FEBRUARI 2017)
}

\author{
Sesar Prabu Dwi Sriyanto ${ }^{1, a)}$, Indah Fajerianti ${ }^{1}$, Amalia Nasrurroh ${ }^{1}$, \\ Nur Baiti Febryana ${ }^{1}$, Indri Ifantyana ${ }^{1}$, Kevin Dwi Wicaksono ${ }^{1}$, Market Sofyan ${ }^{1}$

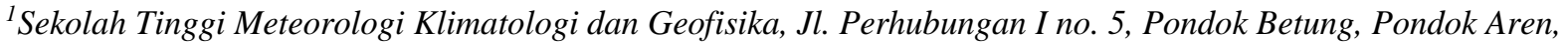 \\ Tangerang Selatan, Kode Pos 15221 \\ Email: ${ }^{a)}$ sesardwis@gmail.com
}

\begin{abstract}
Abstrak
Getaran tanah (ground motion) akibat gempabumi berbahaya karena dapat merobohkan bangunan. Getaran tanah merupakan hasil konvolusi dari fungsi sumber dan fungsi penjalaran gelombang seismik, yang termasuk fungsi tapak lokal pada lokasi sensor. Pada studi ini dianalisis variasi karakter getaran tanah secara spasial dari 7 kejadian gempabumi yang terjadi dalam rentang waktu 9 hingga 13 Februari 2017 di Sumatera Utara. Dari rekaman getaran tanah pada 8 stasiun seismik yang tersebar di sekitar episenter, dihitung nilai PGA (Peak Ground Acceleration) dan PGV (Peak Ground Velocity). Pada 8 stasiun seismik tersebut dianalisis pula kondisi tapak lokalnya menggunakan metode HVSR (Horizontal to Vertical Spectral Ratio) untuk melihat pengaruhnya pada getaran tanah. Secara umum nilai PGA dan PGV berbanding terbalik terhadap jarak episenter. Kondisi tanah yang lunak pada lokasi stasiun seismik menyebabkan terjadi amplifikasi gelombang sehingga terjadi perbesaran nilai PGA dan PGV. Selain itu, arah penyesaran gempabumi juga mempengaruhi nilai puncak getaran tanah. Pada kasus ini, PGA dan PGV cenderung memiliki nilai yang tinggi pada daerah sebelah Utara episenter sehingga dapat diketahui bahwa daerah tersebut memiliki potensi bahaya seismik yang lebih tinggi daripada sebelah Selatan episenter bila ditinjau dari kejadian dengan sumber sesar tersebut.
\end{abstract}

Kata-kata kunci: variasi spasial, nilai puncak getaran tanah, efek tapak lokal, arah penyesaran

\begin{abstract}
The ground motion that caused bythe earthquakee is dangerous since it can break down buildings. It is the result of convolution of source function and raypath function of seismic wave, including local site function on seismometer location. The aim of this study is to analyze the characteristic variations of spatial ground motion from 7 earthquake events happened from 9 till 13 on February 2017 in North Sumatra. Based on the recording of ground motion from 8 seismic stations around the epicenter, the value of the PGA (Peak Ground Acceleration) and PGV (Peak Ground Velocity) can be calculated. The analysis of local site and its influence to ground motion is also calculated using HVSR (Horizontal to Vertical Spectral Ratio) method. Generally, the value of the PGA and PGV are inversely equal to epicenter distance. The soft soil condition in seismic stations cause wave amplification resulted in the magnification of PGA and PGV value. Besides, the rupture directivity can also affect the value of peak ground motion. In this case, the value of the PGA and PGV tend to be high in the north area of the epicenter. It indicates that north area has the highest potential for seismic hazard than the south area if it is reviewed on this source.
\end{abstract}


Keywords: spatial variation, peak ground motion, local site effect, rupture directivity

\section{PENDAHULUAN}

Gempabumi merupakan salah satu bencana alam yang sering terjadi di Indonesia. Menurut [1], secara statistik rata-rata terjadi 2 kali gempabumi merusak dalam 1 tahun. Bencana ini menjadi berbahaya karena efek getaran di tanah permukan yang mengakibatkan bangunan dipaksa untuk berdeformasi sehingga menimbulkan kerusakan [2]. Getaran tanah (ground motion) merupakan hasil konvolusi dari fungsi sumber gempabumi dan fungsi media penjalaran gelombang seismik, yang termasuk didalamnya juga fungsi tapak lokal pada lokasi sensor pencatat [3]. Menurut [2], getaran tanah penting untuk dipelajari karena tingkat getaran tanah dapat menggambarkan tingkat kerusakan yang terjadi pada bangunan di permukaan. Selain itu kajian terhadap karakteristik getaran tanah juga dapat digunakan untuk penentuan building code suatu daerah.

Berdasarkan penelitian [4] yang melakukan kajian variabilitas rekaman getaran tanah pada sensor dekat episenter, nilai puncak getaran tanah yang terdiri dari nilai puncak percepatan tanah (Peak Ground Acceleration atau PGA) dan nilai puncak kecepatan tanah (Peak Ground Velocity atau PGV) bervariasi secara azimuthal. Efek ini menyebabkan nilai PGA dan PGV memiliki nilai tertinggi pada sensor yang searah penyesaran (rupture directivity). Arah penyesaran ini berkaitan dengan pola radiasi gelombang seismik dari sumber gempabumi, yang dapat diketahui dari arah slip gempabumi.

Pada [5] juga menunjukkan adanya variasi spasial rekaman getaran tanah akibat gempabumi Nepal 2015. Secara signifikan terdapat perbedaan karakteristik sinyal hasil rekaman pada arah forward dengan arah backward. Dari Gambar 1. dapat dilihat bahwa durasi getaran tanah pada arah forward relatif lebih pendek daripada arah backward. Selain itu dapat dilihat pula nilai PGA pada arah forward lebih besar daripada arah backward, yang ditunjukkan dari nilai PGA di stasiun KSN yang memiliki jarak episenter $401 \mathrm{~km}$ hampir sama dengan catatan PGA di stasiun BRP yang memiliki jarak episenter $270 \mathrm{~km}$.

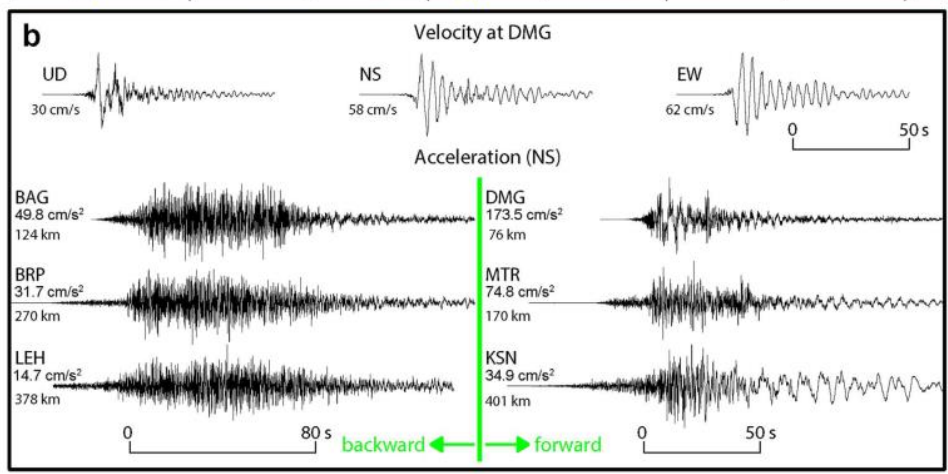

GAMBAR 1. Rekaman kecepatan tanah di stasiun DMG selama gempabumi utama Nepal 2015 (sisi atas), dan rekaman percepatan tanah dari 6 stasiun sekitar episenter gempabumi Nepal dengan sebelah kiri dan kanan masing-masing merupakan stasiun yang terletak pada arah backward dan forward [5]

Pada penelitian ini dilakukan analisis data sinyal rangkaian gempabumi Sumatera Utara yang terjadi pada tanggal 9-13 Februari 2017. Selama kurun waktu tersebut terjadi 7 kejadian gempabumi dengan episenter yang berdekatan dan magnitudo yang hampir sama (antara 4,2 hingga 5,2). Meskipun bukan tergolong gempabumi dengan magnitudo besar, namun rangkaian gempabumi ini dapat menimbulkan getaran yang cukup kuat karena episenternya terdapat di daratan dan tidak jauh dari pusat Kota Medan. Kajian ini dilakukan untuk meninjau wilayah-wilayah yang terdampak akibat kejadian gempabumigempabumi tersebut dan untuk melakukan penilaian potensi bahaya seismik di wilayah Sumatera bagian Utara yang ditimbulkan dari sumber sesar tersebut. 


\section{METODE}

Data yang digunakan merupakan data sinyal gempabumi yang diperoleh dari webdc BMKG. Sinyal yang diunduh merupakan rekaman 8 stasiun seismik yang berlokasi disekitar episenter gempabumi. Stasiun-stasiun seismik tersebut antara lain GSI, KCSI, LASI, PSI, SBSI, SNSI, TRSI, dan TSI. Stasiunstasiun yang termasuk jaringan seismik nasional ini dipilih dengan pertimbangan lokasi stasiun yang konfigurasinya mengitari episenter gempabumi.

Karakteristik getaran tanah yang ditinjau adalah nilai PGA dan PGV, yang merupakan nilai maksimum dari catatan sinyal gempabumi di masing-masing stasiun. Untuk dapat meninjau karakteristik getaran tanah yang terjadi pada masing-masing kejadian gempabumi, pertama yang dilakukan adalah melakukan koreksi respon instrumen. Menurut [6] koreksi respon instrumen dilakukan dengan cara mendekonvolusi data mentah sinyal terhadap fungsi transfer instrumen yang berupa informasi poles dan zeros seismometer.

Selanjutnya dilakukan pula koreksi terhadap efek tapak lokal pada lokasi masing-masing stasiun. Hal ini dilakukan agar informasi PGA dan PGV tidak terpengaruh oleh faktor tapak lokal di lokasi seismometer. Koreksi efek tapak lokal dilakukan dengan membagi nilai PGA dan PGV observasi terhadap faktor amplifikasi gelombang yang terjadi di masing-masing stasiun [4]. Nilai amplifikasi gelombang didapatkan dengan menggunakan metode HVSR (Horizontal to Vertical Spectral Ratio) data mikrotremor. Menurut [7], metode HVSR memperlihatkan suatu kesamaan antara rasio spektra horizontal ke vertikal dengan transfer gelombang dari batuan dasar ke permukaan. Periode dominan dan nilai puncak dari spektra rasio (H/V) masing-masing menunjukkan periode natural dan faktor amplifikasi lapisan tanah.

Data sinyal yang telah terkoreksi efek tapak lokal selanjutnya digunakan untuk mengetahui variasi spasial getaran tanah yang dipengaruhi oleh arah penyesaran. Informasi arah penyesaran diperoleh dari momen tensor gempabumi Sumatera Utara 16 Januari 2017 hasil analisis Global CMT, yang ditunjukkan pada Gambar 2. Episenter gempabumi Sumatera Utara 16 Januari 2017 terletak di koordinat 3,31 ${ }^{\circ} \mathrm{LU}$ $98,43^{\circ} \mathrm{BT}$. Posisi episenter gempabumi ini berlokasi tidak jauh dari episenter rangkaian gempabumi yang diteliti sehingga dapat diasumsikan memiliki struktur patahan yang sama.

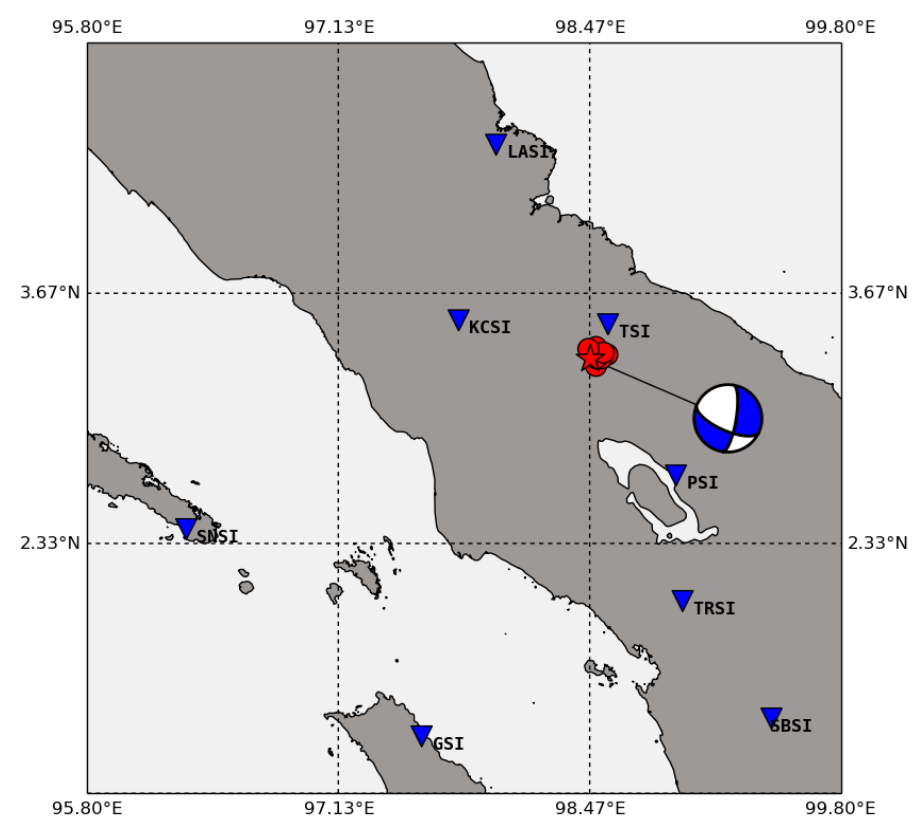

Gambar 2. Sebaran stasiun (segitiga warna biru) dan lokasi episenter (lingkaran warna merah) rangkaian gempabumi 9-13 Februari 2017. Bola mekanisme fokal menunjukkan mekanisme sumber gempabumi Sumatera Utara 16 Januari 2017 (bintang warna merah). 


\section{HASIL DAN PEMBAHASAN}

Dari hasil observasi PGA dan PGV akibat rangkaian gempabumi Sumatera Utara pada 8 stasiun di sekitar episenter dapat dilihat bahwa nilai logaritmik PGA dan PGV menurun secara linier terhadap jarak episenter dengan gradien garis masing-masing -0.0094 dan -0.0083, seperti yang ditunjukkan pada Gambar 3. Nilai puncak getaran tanah, baik PGA maupun PGV, selalu memiliki nilai tertinggi di stasiun TSI, yang merupakan stasiun terdekat dari episenter dengan jarak antara 15,21 hingga 25,56 km. Nilai PGA dan PGV tertinggi yang tercatat di stasiun TSI masing-masing sebesar $0,00578 \mathrm{~m} / \mathrm{s} 2$ dan 0,00915 m/s dari kejadian gempabumi 13 Februari 2017 dengan origin time pukul 20:36:00 WIB dan magnitudo 5,2. Sebaliknya, PGA dan PGV di stasiun SNSI merupakan nilai puncak getaran tanah terkecil karena jaraknya yang cukup jauh dengan rata-rata jarak episenter 263,66 km.

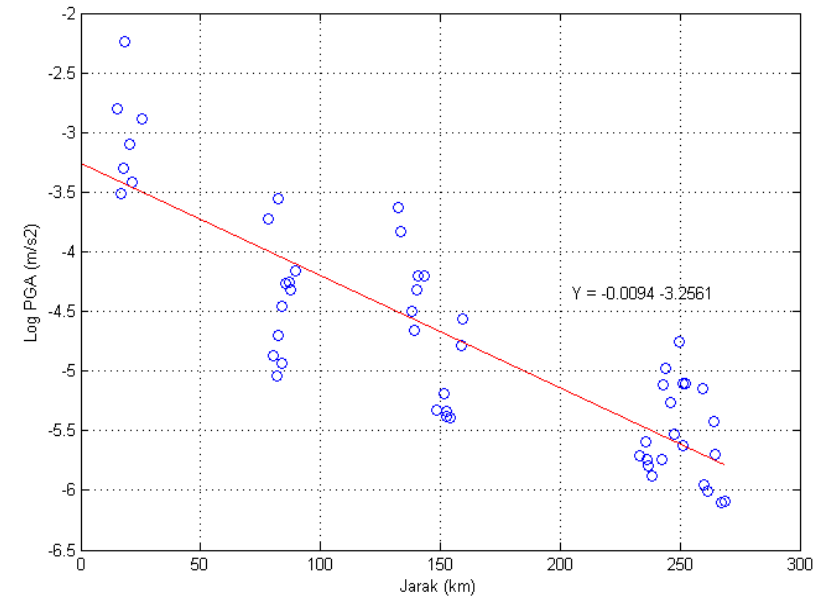

(a)

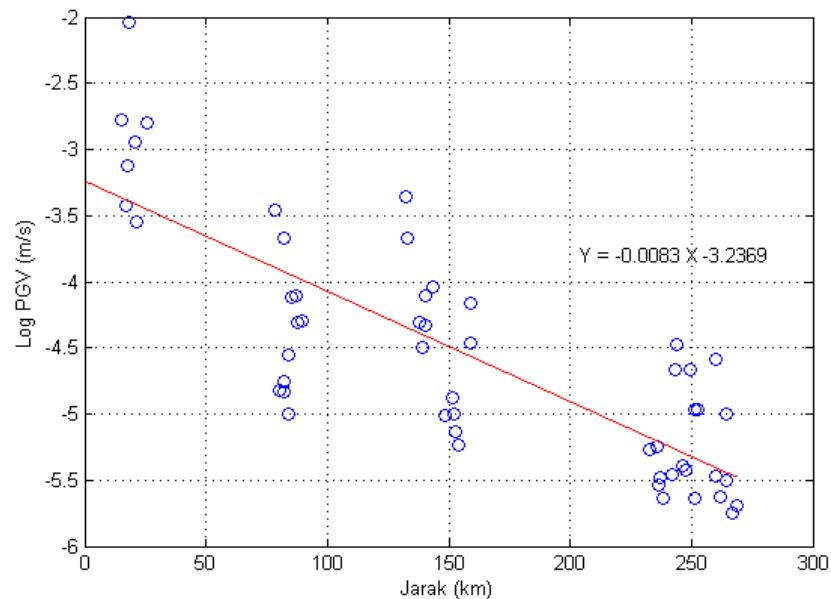

(b)

Gambar 3. Grafik hubungan jarak episenter terhadap log PGA (a) dan log PGV (b).

Pada Gambar 4. ditunjukkan adanya ketidakselarasan nilai puncak getaran tanah terhadap jarak episenter. Hal ini bisa terjadi karena adanya amplifikasi gelombang akibat kondisi tanah lokasi seismometer dan faktor arah penyesaran. Hasil analisa metode HVSR menunjukkan bahwa semua stasiun memiliki nilai amplifikasi lebih dari 1,00. Nilai amplifikasi tertinggi terjadi di stasiun TRSI dengan nilai amplifikasi 4,67 sedangkan amplifikasi terendah pada stasiun PSI dengan nilai amplifikasi 1,43. Faktor amplifikasi ini cukup terlihat pada stasiun KCSI dan LASI yang memiliki perbedaan jarak yang cukup jauh namun nilai PGA dan PGV yang terekam memiliki nilai yang hampir sama. Dari hasil analisis HVSR pada data mikrotremor di kedua stasiun tersebut, didapat bahwa stasiun KCSI memiliki nilai amplifikasi gelombang yang lebih rendah daripada stasiun LASI, dengan nilai masing-masing adalah 1,579 dan 2,4829. Stasiun KCSI yang terletak di daerah pegunungan memiliki kondisi tanah yang lebih kaku daripada stasiun LASI yang terletak di dataran rendah dekat pantai dengan kondisi tanah yang lunak. Setelah dilakukan koreksi terhadap efek tapak lokal, nilai PGA dan PGV pada kedua stasiun tidak berubah secara signifikan dan masih memiliki selisih nilai yang kecil. Hal ini diduga karena adanya faktor arah penyesaran. 


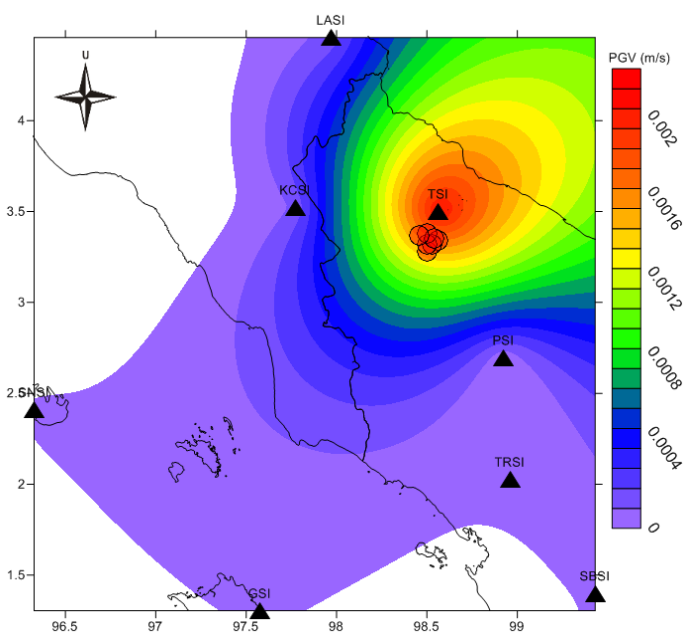

(a)

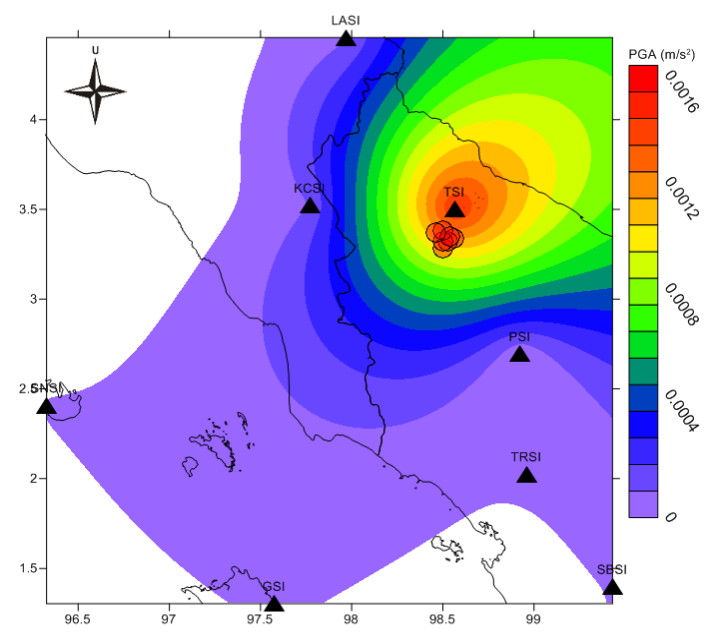

(b)

Gambar 4. Kontur nilai rata-rata (a) PGV dan (b) PGA observasi dari 7 kejadian gempabum

Sesuai dengan hasil analisa Global CMT, gempabumi Sumatera Utara 16 Januari 2017 memiliki strike $114^{\circ}$, dip $57^{\circ}$, slip $-154^{\circ}$. Dari informasi tersebut dapat diketahui bahwa sumber sesar dari rangkaian gempabumi ini memiliki arah strike Tenggara-Barat Laut dan pergerakan slip ke arah Barat Laut. Stasiunstasiun yang berada di arah pergerakan slip atau arah penyesaran, seperti KCSI dan LASI, cenderung memiliki PGA dan PGV lebih tinggi daripada stasiun-stasiun lainnya. Apabila dilakukan perbandingan, Stasiun KCSI yang berada pada arah penyesaran dengan jarak episenter rata-rata 84,873 km selalu memiliki nilai puncak getaran tanah yang lebih tinggi daripada stasiun PSI yang memiliki jarak episenter lebih dekat dengan rata-rata jarak episenter $82,043 \mathrm{~km}$. Pada Gambar 5. ditunjukkan sinyal gempabumi tanggal 9 Februari 2017 dengan OT 22:04:27 WIB dan magnitudo 4,2 yang terekam di stasiun KCSI dan PSI, dimana rekaman sinyal pada stasiun KCSI jauh lebih besar daripada di stasiun PSI.
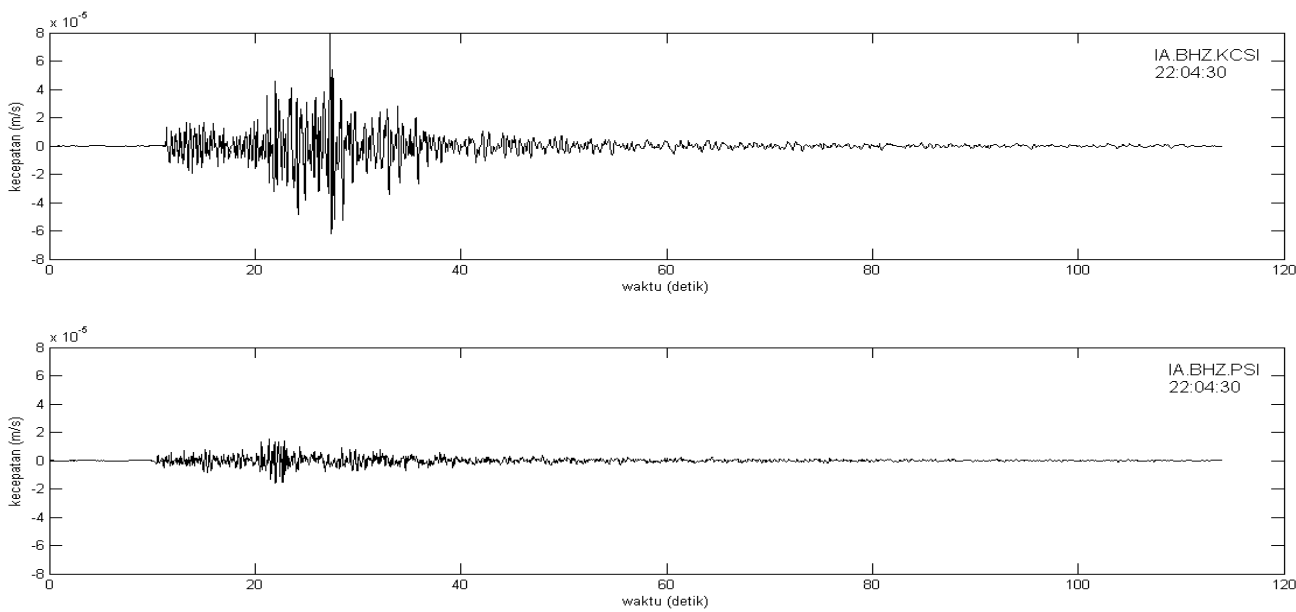

Gambar 5. Sinyal komponen Z stasiun KCSI (atas) dan stasiun PSI (bawah)

Pola kontur sebaran nilai puncak getaran tanah dari semua kejadian gempabumi yang dianalisis menunjukkan kemiripan, dimana nilai PGA dan PGV dari seluruh kejadian gempabumi memiliki kecenderungan lebih besar pada daerah arah penyesaran. Selain dapat mengetahui pengaruh arah penyesaran gempabumi terhadap getaran tanah, hal ini juga dapat menunjukkan bahwa gempabumi dengan sumber sesar ini memiliki potensi bahaya seismik yang tinggi pada daerah sebelah Utara episenter. 


\section{SIMPULAN}

Secara spasial, nilai puncak getaran tanah berbanding terbalik dengan jarak episenter. Selain itu, faktor tapak lokal juga mempengaruhi puncak getaran tanah karena menyebabkan amplifikasi gelombang seismik pada tanah yang lunak. Arah penyesaran sumber gempabumi juga menyebabkan nilai puncak getaran tanah cenderung lebih tinggi pada daerah yang searah dengan arah penyesaran. Pada kasus rangkaian gempabumi Sumatera Utara, nilai puncak getaran tanah cenderung memiliki nilai yang tinggi pada daerah sebelah Utara episenter sehingga dapat diketahui bahwa daerah tersebut memiliki potensi bahaya seismik yang lebih tinggi daripada sebelah Selatan episenter bila ditinjau dari kejadian dengan sumber sesar tersebut.

\section{UCAPAN TERIMAKASIH}

Penulis mengucapkan terima kasih kepada Badan Meteorologi Klimatologi dan Geofisika (BMKG) atas data seismik yang dapat digunakan dalam penelitian ini. Selanjutnya, ucapan terima kasih juga ditujukan kepada Civitas Akademika STMKG yang telah mendukung kegiatan penelitian ini.

\section{REFERENSI}

[1] Sunarjo, et al. Gempa Bumi Indonesia, Edisi Populer. Jakarta: Badan Meteorologi Klimatologi dan Geofisika, 2010.

[2] W. Pawirodikromo, Seismologi Teknik dan Rekayasa Kegempaan. Yogyakarta: Pustaka Pelajar, 2012.

[3] S. Stein dan M. Wysession, An Introduction to Seismology, Earthquake, and Earth Structure. USA: Blackwell Publishing Ltd, 2003.

[4] G. Cultrera, et al. "Directivity Effects for Moderate-Magnitude Earthquake (Mw 5.6-6.0) during the 1997 Umbria-Marche Sequence, Central Italy," in Tectonophysics, 2008. doi : 10.1016/j.tecto.2008.09.022.

[5] K. Koketsu, et al. "Widespread Ground Motion Distribution Caused by Rupture Directivity during the 2015 Gorkha, Nepal Earthquake," in Sci. Rep. 6, 28536, 2015. doi : $10.1038 /$ srep28536.

[6] P. K. G. A. Negara, "Koreksi Respons Instrumen pada Seismometer Co-Located dan Penerapannya pada Seismometer Non Co-Located untuk Menganalisis Faktor yang Mempengaruhi Seismogram," Skripsi. STMKG, Tangerang Selatan, Indonesia, 2016.

[7] Y. Nakamura, "A Method for Dynamic Characteristics Estimation of Subsurface Using Microtremors on the Ground Surface," in Quart. Rep. of RTRI, 30:1, 25-33, 1989. 